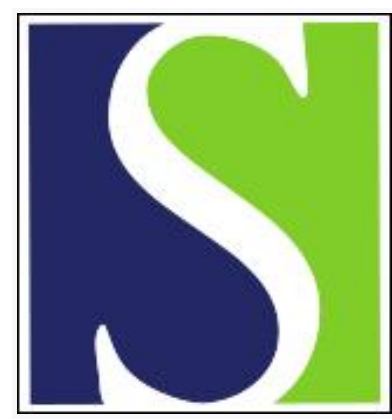

Scand J Work Environ Health 2005;31(3):179-183

https://doi.org/10.5271/sjweh.867

Issue date: Jun 2005

Shift work and the risk of diabetes mellitus among Japanese male factory workers

by Morikawa Y, Nakagawa H, Miura K, Soyama Y, Ishizaki M, Kido T, Naruse $Y$, Suwazono $Y$, Nogawa $K$

Affiliation: Department of Public Health, Kanazawa Medical University, 1-1 Daigaku, Uchinada-machi, Kahoku-gun, Ishikawa, Japan, 920-0293. ymj@@kanazawa-med.ac.jp

The following articles refer to this text: 2006;32(6):502-514;

2007;33(1):45-50; 2008;34(1):33-39; 2009;35(4):309-318; 2011;37(4):263-275; 2012;38(4):337-342; 2015;41(6):569-578

Key terms: cohort study; diabetes mellitus; factory worker; glucose tolerance; glycated hemoglobin; Japan; man; shift work

This article in PubMed: www.ncbi.nlm.nih.gov/pubmed/15999569

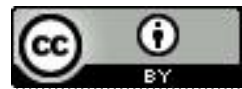




\title{
Shift work and the risk of diabetes mellitus among Japanese male factory workers
}

\author{
by Yuko Morikawa, PhD, ${ }^{1}$ Hideaki Nakagawa, PhD, ${ }^{1}$ Katsuyuki Miura, PhD, ${ }^{1}$ Yoshiyuki Soyama, PhD, ${ }^{1}$ Masao \\ Ishizaki, PhD, ${ }^{2}$ Teruhiko Kido, PhD, ${ }^{3}$ Yuchi Naruse, PhD, ${ }^{4}$ Yasushi Suwazono, PhD, ${ }^{5}$ Koji Nogawa, PhD ${ }^{5}$
}

\begin{abstract}
Morikawa Y, Nakagawa H, Miura K, Soyama Y, Ishizaki M, Kido T, Naruse Y, Suwazono Y, Nogawa K. Shift work and the risk of diabetes mellitus among Japanese male factory workers. Scand $J$ Work Environ Health 2005;31(3):179-183.
\end{abstract}

Objectives This study investigated whether shift work is a risk factor for the development of diabetes mellitus.
Methods The workers, 2860 men in a sash and zipper factory in the Toyama prefecture of Japan, were followed
for 8 years, and the incidence rate of diabetes mellitus was determined. The cohort contained fixed daytime blue-
collar workers, shift blue-collar workers, and white-collar workers. The workers were considered to have
diabetes mellitus if, in their annual health examination, they had a glycated hemoglobin level of $\geq 6.1$ or if the
diagnosis had been made by a hospital physician. The relative risks were estimated by Cox's proportional
hazards regression model.

Results Among the 2860 workers, there were 87 cases of new-onset diabetes mellitus, resulting in an incidence rate of 4.41 per 1000 person-years. The age-adjusted incidence was highest for the two-shift workers and lowest for the white-collar workers. The relative risk of diabetes mellitus for the two-shift workers and the three-shift workers compared with the fixed daytime workers was 1.73 and 1.33 , respectively, after adjustment for all the confounding factors, but these values were not statistically significant. When the white-collar workers were used as a reference group, a significantly increased risk of diabetes mellitus was found for the two-shift workers (relative risk was 2.01 after adjustment for all confounding factors), but not for the three-shift workers or the fixed daytime blue-collar workers.

Conclusions The study suggests that shift work is a risk factor for the onset of diabetes mellitus and that there is a different risk associated with different shift schedules.

Key terms cohort study; glucose tolerance; glycated hemoglobin.

Shift work has been associated with an increased risk of cardiovascular disease (1-3). Four pathways (ie, the mismatch of circadian rhythms, social disruption, behavioral changes, and changes in biomarkers) are considered factors that predispose shift workers to this disease (1). Changes in the biomarkers may be related to a mismatch of the circadian rhythm and behavioral changes (4). Some studies have shown that obesity, high triglyceride levels, and low concentrations of high-density lipoprotein (HDL) cholesterol seem to cluster together more often in shift workers than in day workers. This trend may indicate an association between shift work and the metabolic syndrome (5-10). In the metabolic syndrome, the effects of shift work on glucose tolerance are not understood, although there have been several cohort studies examining this issue. Insulin sensitivity is known to be lower during the night than during the day $(11,12)$. Furthermore, sleep debt has a harmful impact on carbohydrate metabolism and endocrine function (13). Some experimental studies that were carried out to investigate postprandial hormone and metabolic responses during simulated shift work $(14,15)$ found decreased glucose tolerance during the night. Therefore, it is legitimate to presume that shift work may have some effect on glucose tolerance. The objective of this cohort study was to investigate whether shift work is a risk factor for the onset of diabetes mellitus and whether there are different risks associated with different shift schedules.

1 Department of Public Health, Kanazawa Medical University, Ishiakawa, Japan.

2 Kanazawa Medical University, Ishikawa, Japan.

3 Kanazawa University, Kanazawa, Japan.

4 Toyama Medical and Pharmaceutical University, Toyama, Japan.

5 Chiba University, Chiba, Japan.

Reprint requests to: Dr Yuko Morikawa, Department of Public Health, Kanazawa Medical University, 1-1 Daigaku, Uchinada-machi, Kahoku-gun, Ishikawa, Japan, 920-0293. [E-mail: ymjr@kanazawa-med.ac.jp] 


\section{Study population and methods}

\section{Study population}

The study population included male blue- and whitecollar workers who were between 19 and 49 years of age, worked in a sash and zipper factory in the Toyama prefecture of Japan, and underwent health check-ups in 1993 (participation rate of $95 \%$ ). The target population consisted of 3106 workers, and the 246 workers with a history of diabetes mellitus or glucose intolerance or a glycated hemoglobin (HbA1c) level of $\geq 5.6 \%$ at baseline (over the normal range) were excluded. Therefore, the cohort consisted of 2860 men who were followed annually until they were diagnosed as having diabetes mellitus or until the end of 2001. From 1994 to 2001, annual screening tests were carried out, including $\mathrm{HbA1c}$, blood glucose measurement, and the administration of medical history questionnaires. The questionnaire in 1993 contained questions regarding the workers' history of diabetes mellitus and family history of diabetes mellitus, as well as health-related behavior, such as smoking, drinking, dietary habit, and leisuretime physical activities.

\section{Occupations}

Information on the occupational category and the shift work schedule at baseline was obtained from a questionnaire. Jobs were classified into two types (blue-collar and white-collar). All white-collar workers were engaged in fixed daytime work. The blue-collar workers were engaged in mainly the following three types of work schedules: fixed daytime work, rotating two-shift work, and rotating three-shift work. The three-shift workers' schedule rotated counterclockwise with twothirds of them engaged in a noncontinuous shift system (5 day shifts, 5 night shifts, and 5 evening shifts) and one-third of them working a continuous-shift system (3 or 4 day shifts, 3 or 4 night shifts, and 3 or 4 evening shifts, with one rest day between successive shifts). Both rotating three-shift systems changed shifts at 0800 , 1630 , and 0015 or at 0630,1300 , and 2130 . Most of the rotating two-shift workers did day shifts and evening shifts with a noncontinuous shift system. There were 1099 fixed daytime blue-collar workers, 228 two-shift workers, 492 three-shift workers, and 1041 white-collar workers. Certain jobs, such as those involving the operation of machines that melt, heat, mix, or cast, are routinely performed by three-shift workers, while jobs involving processing or the construction of aluminum products are done by fixed daytime workers or two-shift workers.

\section{Baseline characteristics}

The baseline characteristics and information on healthrelated behavior are shown in table 1 . The baseline body mass index (BMI) and HbA1c levels were similar among the occupational groups. The prevalence of unfavorable health-related behavior, such as smoking, habitual drinking, and lack of regular leisure-time physical exercise, was higher for the blue-collar workers than for the white-collar workers. Among the blue-collar workers, the prevalence of regular physical exercise was lower for the shift workers than for the fixed daytime workers.

\section{Endpoint determination}

The determination of the presence of diabetes mellitus was based on an HbA1c of $\geq 6.1$ or a diagnosis having been made by hospital physicians. Although blood glucose levels were also measured during the screening, they were not always taken as fasting samples. Therefore, we did not use the blood glucose level as a diagnostic criterion.

\section{Statistics}

The incidence rates of diabetes mellitus were expressed per 1000 person-years. Age-adjusted rates were calculated with the indirect method of standardization by using all blue-collar workers as a standard population. The relative risks and their 95\% confidence intervals for diabetes mellitus among the shift workers were calculated after adjustment for confounding factors using Cox's proportional hazards regression model. The baseline characteristics used for the analysis were age, BMI, family history of diabetes mellitus (limited to first-degree

Table 1. Baseline characteristics for each occupational category. (BMI = body mass index, $\mathrm{HbA1C}=$ glycated hemoglobin)

\begin{tabular}{|c|c|c|c|c|c|c|c|c|c|c|}
\hline \multirow[t]{2}{*}{ Occupational category } & \multicolumn{2}{|c|}{ Age (years) } & \multicolumn{2}{|c|}{$\mathrm{BMI}$} & \multicolumn{2}{|c|}{$\mathrm{HbA1c}$} & \multirow{2}{*}{$\begin{array}{c}\text { Family } \\
\text { history }{ }^{\mathrm{a}} \\
(\%)\end{array}$} & \multirow{2}{*}{$\begin{array}{c}\text { Current } \\
\text { smoking } \\
(\%)\end{array}$} & \multirow{2}{*}{$\begin{array}{c}\text { Habitual } \\
\text { drinking }{ }^{\mathrm{b}} \\
(\%)\end{array}$} & \multirow{2}{*}{$\begin{array}{c}\text { No } \\
\text { exercise } \\
(\%)\end{array}$} \\
\hline & Mean & SD & Mean & SD & Mean & SD & & & & \\
\hline \multicolumn{11}{|l|}{ Blue-collar workers } \\
\hline Fixed-daytime workers $(\mathrm{N}=1099)$ & 35.3 & 8.5 & 22.4 & 2.7 & 4.87 & 0.32 & 7.3 & 66.2 & 41.1 & 64.5 \\
\hline Two-shift workers ( $\mathrm{N}=228)$ & 33.5 & 8.6 & 22.5 & 3.2 & 4.83 & 0.34 & 8.0 & 60.0 & 36.4 & 71.7 \\
\hline Three-shift workers $(\mathrm{N}=492)$ & 33.7 & 8.5 & 22.6 & 2.9 & 4.87 & 0.30 & 8.0 & 67.4 & 41.4 & 68.6 \\
\hline White-collar workers $(\mathrm{N}=1041)$ & 33.7 & 7.6 & 22.7 & 2.7 & 4.86 & 0.32 & 9.2 & 52.9 & 39.4 & 60.2 \\
\hline
\end{tabular}

a Limited to first-degree relatives.

b Drinking $\geq 6$ times/week.

c Participating in leisure-time physical exercise $<1 /$ week. 
relatives), and health-related behavior. The software package used for the analysis was SPSS 11.0 (SPSS Inc, Chicago, IL, USA).

\section{Results}

Table 2 shows the age-adjusted incidence rates of diabetes mellitus by occupational category. Among the 2860 workers, there were 87 cases of new onset diabetes mellitus, for an incidence rate of 4.41/1000 personyears. Among these 87 cases, 51 were diagnosed both with respect to HbA1c level and medical history, 21 were diagnosed according to the $\mathrm{HbA} 1 \mathrm{c}$ level alone, and 15 were diagnosed with regard to medical history alone. The age-adjusted incidence rate for blue-collar workers was 5.94/1000 person-years. Among blue-collar workers, the incidence rate was the highest for the two-shift workers $(6.84 / 1000$ person-years), followed by the three-shift workers (5.32/1000 person-years) and the fixed daytime workers (4.23/1000 person-years). The incidence of diabetes mellitus among the white-collar workers was 3.53/1000 person-years.

Table 3 shows the relative risks of the demographic factors and health-related behavior for diabetes mellitus using Cox's proportional hazards regression model. Age, BMI, and smoking statistically significantly increased the risk of diabetes mellitus. A family history of diabetes showed a trend towards increasing the risk of diabetes mellitus, although this trend was not statistically significant. Lack of leisure-time physical exercise and habitual drinking ( $\geq 5$ times/week) were not associated with diabetes mellitus.

Table 4 shows the relative risks of diabetes mellitus for the occupational categories using Cox's proportional hazards regression model. The relative risks of diabetes mellitus for the shift workers were calculated by using the fixed daytime workers as reference. The relative risk of diabetes mellitus for the two-shift workers compared with the fixed daytime workers was 1.70 after adjustment for age alone, 1.80 after adjustment for age, BMI and family history, and 1.73 after adjustment for all the confounding factors, but none of these were statistically significant. Of note, the relative risks of the threeshift workers compared with the fixed daytime workers were smaller than those of the two-shift workers.

When the white-collar workers in the same factory were used as a reference group, a statistically significant increase in the risk of diabetes mellitus was found for the two-shift workers. In fact, adjustment for age, BMI, and family history, as well as for all confounding factors, including health-related behavior (smoking, drinking and leisure-time physical activity), resulted in a statistically significantly increased risk of diabetes mellitus among the two-shift workers when they were

compared with the white-collar workers. Finally, when compared with the white-collar workers, the three-shift workers and the fixed daytime workers showed no difference in the risk for diabetes mellitus when the results were adjusted for age, BMI, and family history or for all the confounding factors.

These results suggest that shift work, particularly two-shift work, is a risk factor for diabetes mellitus. An increased risk was apparent when comparisons were made with the white-collar workers, but not with the fixed daytime blue-collar workers. The increased risk

Table 2. Incidence rate a of diabetes mellitus by occupational category. ( $95 \% \mathrm{Cl}=95 \%$ confidence interval)

\begin{tabular}{lrrrrrrr}
\hline Occupational category & $N$ & $\begin{array}{c}\text { Per- } \\
\text { son- } \\
\text { years }\end{array}$ & $\begin{array}{c}\text { Cases Crude } \\
\text { inci- } \\
\text { dence } \\
\text { rate }\end{array}$ & $\begin{array}{c}\text { Inci- } \\
\text { rate }\end{array}$ & $95 \% \mathrm{Cl}$ \\
\hline Blue-collar workers & & & & & & & \\
$\quad$ Total & 1819 & 12853 & 64 & 4.98 &.. &.. \\
$\quad$ Fixed daytime & 1099 & 7675 & 34 & 4.43 & 4.23 & $3.24-6.08$ \\
$\quad$ Shift workers & 720 & 5178 & 30 & 5.79 & 6.23 & $4.60-9.06$ \\
$\quad$ Two-shift workers & 228 & 1608 & 11 & 6.84 & 7.04 & $3.61-11.93$ \\
$\quad$ Three-shift workers & 492 & 3570 & 19 & 5.32 & 5.83 & $3.76-9.00$ \\
White-collar workers & 1041 & 6877 & 23 & 3.34 & 3.53 & $2.53-5.42$ \\
\hline
\end{tabular}

a Per 1000 person-years.

${ }^{\mathrm{b}}$ Adjusted for age, calculated by the indirect method of standardization using all blue-collar workers as a standard population.

Table 3. Relative risks (RR) of the demographic factors a and health-related behavior for diabetes mellitus according to Cox's proportional hazard model. (95\% Cl = 95\% confidence interval)

\begin{tabular}{llcc}
\hline Factor & Category & $\mathrm{RR}$ & $95 \% \mathrm{Cl}$ \\
\hline Age & Linear (each 1 year increase) & 1.07 & $1.04-1.10$ \\
Body mass index & Linear (each 1 increase) & 1.14 & $1.06-1.23$ \\
Family history & + versus - & 1.69 & $0.92-3.12$ \\
Drinking & Almost everyday versus others & 0.64 & $0.40-1.01$ \\
Smoking & + versus - & 1.81 & $1.11-2.94$ \\
Physical exercise & $<1$ time/week versus others & 0.96 & $0.61-1.51$ \\
\hline
\end{tabular}

a All factors were put into the model together.

Table 4. Relative risks (RR) of diabetes mellitus by the occupational categories according to Cox's proportional hazard model. (95\% Cl $=95 \%$ confidence interval)

\begin{tabular}{|c|c|c|c|c|c|c|}
\hline & $\mathrm{RR}^{\mathrm{a}}$ & $95 \% \mathrm{Cl}$ & $\mathrm{RR}^{\mathrm{b}}$ & $95 \% \mathrm{Cl}$ & $\mathrm{RR}^{\mathrm{c}}$ & $95 \%$ \\
\hline \multicolumn{7}{|l|}{ Blue collar workers } \\
\hline Fixed daytime workers & & .. & 1 & .. & 1 & \\
\hline Two-shift workers & 1.70 & $0.86-3.36$ & 1.80 & $0.91-3.55$ & 1.73 & $0.85-3$ \\
\hline Three-shift workers & 1.33 & $0.76-2.34$ & 1.33 & $0.75-2.34$ & 1.33 & $0.74-2$ \\
\hline $\begin{array}{l}\text { White-collar workers } \\
\text { Blue-collar workers }\end{array}$ & 1 & .. & 1 & .. & 1 & \\
\hline Fixed daytime workers & 1.10 & $0.65-1.86$ & 1.15 & $0.69-1.93$ & 31.19 & $0.66-2$ \\
\hline Two-s & 1.93 & & 2.11 & & 22. & 1.00 \\
\hline Three-shift workers & 1.51 & $0.83-2.74$ & 1.53 & $0.85-2.76$ & 61.61 & 0.88 \\
\hline
\end{tabular}


of diabetes mellitus among the two-shift workers, as compared with the white-collar workers, remained even after adjustment for health-related behavior. This finding suggests that the higher risk of diabetes mellitus for two-shift workers is caused primarily by factors not related to lifestyle.

\section{Discussion}

In this 8-year cohort study, we investigated the effects of shift work on the incidence rate of diabetes mellitus. The incidence rate of diabetes mellitus was the highest for the two-shift workers, followed by three-shift workers, fixed daytime workers, and white-collar workers. Although there was a trend towards a higher risk of diabetes mellitus among the shift workers overall, this was not statistically significant when these workers were compared with the fixed daytime workers. However, when compared with the white-collar workers, the two-shift workers had a statistically significant increased risk of diabetes mellitus.

In this study, the onset of diabetes mellitus was diagnosed primarily by documenting an increase in the HbA1c level. HbA1c is widely accepted as a useful index of mean blood glucose in the treatment of patients with diabetes mellitus. However, its use as a screening test for diabetes mellitus has not been widely accepted. On the other hand, fasting blood glucose is accepted as the most sensitive and specific test for diabetes mellitus screening (16). However, we used only HbA1c, because obtaining fasting blood samples from all of the participants during the entire observation period was not feasible. Using both HbA1c and fasting plasma glucose would be the best means of screening for new onset diabetes mellitus. Nevertheless, the sole use of HbA1c has been widely accepted for epidemiologic studies, because epidemiologic studies using HbA1c and fasting plasma glucose as screening tests for undiagnosed diabetes mellitus have found that $\mathrm{HbA} 1 \mathrm{c}$ is both highly specific and convenient (17-19). The Japan Diabetes Society acknowledges the utility of HbA1c as a screening test and has announced that a HbA1c level of $\geq 6.1 \%$ can be used to estimate the prevalence of diabetes mellitus in epidemiologic studies (20), since an HbA1c concentration of $6.1 \%$ corresponds to both a fasting plasma glucose of $7.0 \mathrm{mmol} / \mathrm{l}$ and a 2-hour value of a 75 -gram oral glucose tolerance test of $11.1 \mathrm{mmol} / \mathrm{l}$ (21).

In investigating the effects of shift work on the onset of diabetes mellitus, it is more appropriate to use fixed daytime workers as a reference. Since the physical load of the blue-collar workers in the target factory has been lightened during recent decades, we did not need to consider any differences in the physical exertion of the blue-collar workers; one of the most relevant issues for the blue-collar workers was the work schedule. On the other hand, using white-collar workers as a reference group may have introduced factors other than shift work as confounders, including work characteristics, socioeconomic differences, and lifestyle. However, studies dealing with glucose tolerance or related factors have shown higher risks of diabetes mellitus among sedentary workers, such as managerial workers, drivers, or air traffic controllers, even after adjustment for other confounding factors (22-24). Therefore, the finding that there is a higher risk of diabetes mellitus among blue-collar workers as compared with whitecollar workers is not in accordance with the literature. Therefore, these results may have been caused by factors unrelated to physical workload. Furthermore, the finding that there was no statistically significant difference between fixed daytime blue-collar workers and white-collar workers with respect to the risk of diabetes mellitus also suggests that shift work affects the onset of diabetes mellitus.

The increased risk of diabetes mellitus among the two-shift workers as compared with the white-collar workers may also have been due to a difference in health-related behavior. Smoking and drinking are considered risk factors for diabetes mellitus (25-27). Our study also confirmed that smoking is a risk factor for diabetes mellitus. In this study, shift workers showed a more unfavorable lifestyle than the fixed daytime workers or white-collar workers did. However, the risks of shift work for diabetes mellitus decreased only slightly after adjustment for health-related behavior, and a large part of the risk remained. Therefore, health-related behavioral factors that we did not deal with, such as nutritional intake or a disturbance of biological and physiological circadian rhythm, may have been responsible for the higher risk of diabetes mellitus among two-shift workers. Moreover, since there are several studies showing that $\mathrm{HbA} 1 \mathrm{c}$ concentration is an indicator of job strain (28-30), psychosocial stress related to shift work may have also been responsible. However, the reason for the higher risk of diabetes mellitus among only the two-shift workers (not among the three-shift workers) is not evident. Although there are differences in the prevalence of certain types of health-related behavior, such as smoking and leisure-time physical activity, between twoshift and three-shift workers, adjustment for health-related behavior did not diminish the risk difference between the two types of shift work. Therefore, more information on job strain, dietary habit, and nutritional intake is needed to clarify the difference in the risk of diabetes mellitus between these two types of shift schedules.

Thus far, there have been few prospective studies that have dealt with the effects of shift work on glucose tolerance. Some cross-sectional epidemiologic studies have found an increase in the prevalence of metabolic syndrome among shift workers (5-10). Kawachi et al 
(31) found a relationship between the duration of shift work and diabetes mellitus. Mikuni et al (32) also reported a higher prevalence of diabetes mellitus among shift workers. Our result is consistent with these previous reports. In conclusion, our study suggests that shift work is a risk factor for the onset of diabetes mellitus and that there are different risks associated with different types of shift schedule. Furthermore, since the shift system of the employer studied represents a common type of shift system, used in well-organized Japanese factories, the results of this study can be generalized to represent the effects of shift work on glucose tolerance among all Japanese shift workers.

\section{References}

1. Bøggild H, Knutsson A. Shift work, risk factors and cardiovascular disease [review]. Scand J Work Environ Health 1999;25(2):85-99.

2. Knutsson A. Health disorders of shift workers. Occup Med 2003;53:103-8.

3. Kristensen TS. Cardiovascular diseases and the work environment: a critical review of the epidemiologic literature on nonchemical factors [review]. Scand J Work Environ Health 1989;15:165-79.

4. Knutsson A, Bøggild H. Shiftwork and cardiovascular disease: review of disease mechanisms. Rev Environ Health 2000;15:359-72.

5. Theorell T, Åkerstedt T. Day and night work: changes in cholesterol, uric acid, glucose and potassium in serum and in circadian patterns. Acta Med Scand 1976;200:47-53.

6. Orth-Gomér K. Intervention on coronary risk factors by adapting a shift work schedule to biologic rhythmicity. Psychosom Med 1983;45:407-15.

7. Knutsson A, Åkerstedt T, Jonsson BG. Prevalence of risk factors for coronary artery disease among day and shift workers. Scand J Work Environ Health 1988;14:317-21.

8. Karlsson B, Knutsson A, Lindahl B. Is there an association between shift work and having a metabolic syndrome? results from a population based study of 27,485 people. Occup Environ Med. 2001;58(11):747-52.

9. Karlsson BH, Knutsson AK, Lindahl BO, Alfredsson LS. Metabolic disturbances in male workers with rotating threeshift work. Results of the WOLF study. Int Arch Occup Environ Health. 2003;76:424-30.

10. Nagaya T, Yoshida H, Takahashi H, Kawai M. Markers of insulin resistance in day and shift workers aged 30-59 years. Int Arch Occup Environ Health. 2002;75:562-8.

11. Carroll KF, Nestel PJ. Diurnal variation in glucose tolerance and in insulin secretion in man. Diabetes 1973;22:333-48.

12. Van Cauter E, Desir D, Decoster C, Fery F, Balosse EO. Nocturnal disease of glucose tolerance during constant glucose infusion. J Clin Endocrinol Metab 1989;69:604-11.

13. Spiegel K, Leproult R, van Cauter E. Impact of sleep debt on metabolic and endocrine function. Lancet 1999;354:1435-9.

14. Ribeiro DCO, Hampton SM, Morgan L, Deacon S, Arendt J. Altered postprandial hormone and metabolic responses in simulated shift work environment. J Endocrinol 1998;158:305-10.

15. Lund J, Arendt J, Hampton SM, English J, Morgan LM. Postprandial hormone and metabolic responses amongst shift workers in Antarctica. J Endocrinol 2001:171:557-64.

16. Expert Committee on the Diagnosis and Classification of Diabetes Mellitus, American Diabetes Association. Report of the expert committee on the diagnosis and classification of diabetes mellitus. Diabetes Care 2003;26 suppl 1:S5-20.

17. Rohlfing CL, Harris MI, Little RR, Flegal KM, Wiedmeyer HM, Eberhardt MS, et al. Use of GHb (HbA1c) in screening for undiagnosed diabetes in the U.S. population. Diabetes Care 2000;23:187-91.

18. Takahashi Y, Kuzuya T, Noda M, Ito C, Tsugane S, Kadowaki T. Prevalence of diabetes estimated by plasma glucose criteria combined with standardized measurement of $\mathrm{HbA1c}$ among health checkup participants an Miyako Island, Japan. Diabetes Care 2000;23:1092-6.

19. McCance DR, Hanson RL, Charles MA, Jacobsson LT, Pettitt DJ, Bennett PH, et al. Comparison of tests for glycated haemoglobin and fasting and two hour plasma glucose concentrations as diagnostic methods for diabetes. BMJ 1994; 308:1323-8.

20. The committee of Japan Diabetes Society for the Diagnostic Criteria of Diabetes Mellitus. Report of the Committee of Japan Diabetes Society on the Classification and Diagnostic Criteria of Diabetes Mellitus [in Japanese]. J Jpn Diabetes Soc 1999:42;385-404.

21. Ito C. Study on correlation among fasting plasma glucose, $2-\mathrm{h}$ plasma glucose at GTT and HbA1c. J Jpn Diabetes Soc 1998:41 suppl 2; A63-4.

22. Morikawa Y, Nakagawa H, Ishizaki M, Tabata M, Nishijo M, Miura K, et al. Ten-year follow-up study on the relation between the development of non-insulin-dependent diabetes mellitus and occupation. Am J Ind Med 1997;31:80-4.

23. Cobb S, Rose RM. Hypertension, peptic ulcer and diabetes in air traffic controllers. JAMA 1973;224:489-92.

24. Ng TP. Occupational mortality in Hong Kong, 1973-1983. Int J Epidemiol 1988;17:105-10.

25. Kawakami N, Takatsuka N, Shimizu H, Ishibashi H. Effects of smoking on the incidence of non-insulin dependent diabetes mellitus. Am J Epidemiol 1997;145:103-9.

26. Sairenchi T, Iso H, Nishimura A, Hosoda T, Irie F, Saito Y, et al. Cigarette smoking and risk of type 2 diabetes mellitus among middle-aged and elderly Japanese men and women. Am J Epidemiol 2004;160:158-62.

27. Nakanishi N, Nakamura K, Matsuo Y, Suzuki K, Tatara K. Cigarette smoking and risk for impaired fasting glucose and type 2 diabetes in middle-aged Japanese men. Ann Intern Med 2000;133:183-91.

28. Cesana G, Panza G, Ferrari M, Zanettini R, Arnoldi M, Grieco A. Can glycosylated hemoglobin be a job stress parameter? J Occup Med 1985;27:357-60.

29. Netterstrøm Bo, Sjøl A. Glycated haemoglobin (HbA1c) as an indicator of job strain. Stress Med 1991;7:113-8.

30. Kawakami N, Akachi K, Shimizu H, Haratani T, Kobayashi F, Ishizaki M, et al. Job strain, social support in the workplace, and haemoglobin A1c in Japanese men. Occup Environ Med. 2000; 57:805-9.

31. Kawachi I, Colditz GA, Stampfer MJ, Willett WC, Manson JE, Speizer FE, et al. Prospective study of shift work and risk of coronary heart disease in women. Circulation 1995; 92:3178-82.

32. Mikuni E, Ohoshi T, Hayashi K, Miyamura K. Glucose intolerance in an employed population. Tohoku J Exp Med 1983; 141 suppl:251-6.

Received for publication: 40 April 2004 